\title{
Tobacco Use Epidemiology
}

National Cancer Institute

\section{Source}

National Cancer Institute. Tobacco Use Epidemiology. NCI Thesaurus. Code C19353.

Population-based research studies that assess associations between tobacco use, behavioral and biological factors, and cancer. 